\title{
$\mathrm{HIO}_{\mathrm{x}}-\mathrm{IONO}_{2}$ Dynamics at the Air-Water Interface: Revealing the Existence of a Halogen Bond at the Atmospheric Aerosol Surface
}

\author{
Manoj Kumar, ${ }^{1}$ Tarek Trabelsi, ${ }^{1}$ Juan Carlos Gómez Martín, ${ }^{2}$ Alfonso Saiz-Lopez, ${ }^{3}$ Joseph S. Fran- \\ $\operatorname{cisco}^{1, *}$
}

'Department of Earth and Environmental Science and Department of Chemistry, University of Pennsylvania, Philadelphia, Pennsylvania, USA 19104-6243.

${ }^{2}$ Solar System Department, Andalusian Institute for Astrophysics, CSIC, Granada, Spain, 18008.

3Department of Atmospheric Chemistry and Climate, Institute of Physical Chemistry Rocasolano, CSIC, Madrid, Spain, 28006.

Supporting Information Placeholder

ABSTRACT: Iodine is enriched in marine aerosols, particularly in coastal mid-latitude atmospheric environments, where it initiates the formation of new aerosol particles with iodic acid $\left(\mathrm{HIO}_{3}\right)$ composition. However, particle formation in polluted and semipolluted locations is inhibited when the iodine monoxide radical (IO) is intercepted by $\mathrm{NO}_{2}$ to form the iodine nitrate $\left(\mathrm{IONO}_{2}\right)$. The primary fate of $\mathrm{IONO}_{2}$ is believed to be, besides photolysis, uptake by aerosol surfaces, leading to particulate iodine activation. Herein we have performed Born Oppenheimer molecular dynamics (BOMD) simulations and gas-phase quantum chemical calculations to study the iodine acids-iodine nitrate $\left(\mathrm{HIO}_{\mathrm{x}}(\mathrm{x}=2\right.$ and 3$\left.)-\mathrm{IONO}_{2}\right)$ dynamics at the air-water interface modeled by a water droplet of 191 water molecules. The results indicate that $\mathrm{IONO}_{2}$ does not react directly with these iodine acids, but forms an unusual kind of interaction with them within a few picoseconds, which is characterized as halogen bonding. The halogen bond-driven $\mathrm{HIO}_{3}-\mathrm{IONO}_{2}$ complex at the air-water interface undergoes deprotonation and exists as $\mathrm{IO}_{3}^{-}-\mathrm{IONO}_{2}$ anion whereas the $\mathrm{HIO}_{2}-\mathrm{IONO}_{2}$ complex does not exhibit any proton loss to the interfacial water molecules. The gas-phase quantum chemical calculations suggest that the $\mathrm{HIO}_{3}-\mathrm{IONO}_{2}$ and $\mathrm{HIO}_{2}-\mathrm{IONO}_{2}$ complexes have appreciable stabilization energies, which are significantly enhanced upon deprotonation of iodine acids, indicating that these halogen bonds are fairly stable. These $\mathrm{IONO}_{2}$-induced halogen bonds explain the rapid loss of $\mathrm{IONO}_{2}$ to background aerosol. Moreover, they appear to work against iodide formation. Thus, they may play an important role in enhancing the amount of atmospherically non-recyclable iodine (iodate) in marine aerosol.

Introduction. Understanding the atmospheric chemistry of iodine is important because of its role in ozone depletion and new particle formation ${ }^{1}$. A deeper knowledge of how new particles form and nucleate in the atmosphere will help assessing their impact on human health and global climate. In the global marine boundary layer (MBL), aerosol is enriched in iodine compared to seawater ${ }^{2}$, reflecting a transfer of volatile iodinated gases from the sea surface ${ }^{1}$. In coastal environments, intense emission of iodine precursors results in high iodine monoxide (IO) mixing ratios capable of sustaining the formation of iodine oxides that grow to form iodine oxide particles (IOPs) ${ }^{3}$. This gas-to-particle mechanism is yet to be fully understood. Potentially nucleating species derived from $\mathrm{IO}$ are $\mathrm{I}_{2} \mathrm{O}_{\mathrm{y}}(\mathrm{y}=2,4)^{4,5}$. Iodine oxide clusters may subsequently rearrange to $\mathrm{I}_{2} \mathrm{O}_{5}$, which then hydrates to form iodic acid $\left(\mathrm{HIO}_{3}\right)^{6,7}$. However, gas phase $\mathrm{HIO}_{3}$ has also been identified as a major nucleating species in mid latitude and polar coastal environments, while a role of $\mathrm{HIO}_{2}$ has been suggested as well ${ }^{8}$. We have recently explored a mechanistic framework to explain the formation of $\mathrm{I}_{2} \mathrm{O}_{4}$ and $\mathrm{I}_{2} \mathrm{O}_{5}$ from $\mathrm{HIO}_{2}$ and $\mathrm{HIO}_{3}$ reactions using ab initio calculations and molecular simulations ${ }^{9}$. This mechanism is based on non-covalent interactions between iodine acids and oxides and results in the barrierless formation of IOPs.

Mid-latitude coastal particle formation events are generally less intense in polluted air masse ${ }^{10,11}$ since IO reacts with $\mathrm{NO}_{2}$ forming iodine nitrate $\left(\mathrm{IONO}_{2}\right)$, which is a major iodine reservoir species together with hypoiodous acid (HOI). These compounds may be taken up by aqueous aerosol particles, hydrolyzing and releasing di-halogens on aqueous reaction with available halide anions in the presence of sufficient acidity, resulting in halogen activation ${ }^{12}$. However, the $\mathrm{I}^{-} / \mathrm{IO}_{3}{ }^{-}$ ratio, representative of the amount of recyclable iodine in fresh aerosol, is highly variable and the mechanism controlling this ratio is not understood ${ }^{1}$. The prominent role of $\mathrm{HIO}_{3}$ in aerosol iodine chemistry raises interesting questions: can $\mathrm{IONO}_{2}$ interact with $\mathrm{HIO}_{3}$ (and other species) on the aerosol surface and result in a gas-phase iodine loss process? Can other molecules such as $\mathrm{I}_{2} \mathrm{O}_{3}$ be released to the gas phase? Despite speculations about 
uptake and hydrolysis of $\mathrm{IONO}_{2}$ on aqueous aerosol in the literature ${ }^{12}$, the different steps of this process have never been studied in detail.

In this article, we report the $\mathrm{HIO}_{3}-\mathrm{IONO}_{2}$ and $\mathrm{HIO}_{2}-\mathrm{IONO}_{2}$ dynamics at the air-water interface using Born-Oppenheimer molecular dynamics (BOMD) simulations. The air-water interface is a simpler model of the aqueous surfaces, which are prevalent in the atmosphere and provide a unique microenvironment for promoting chemistries, which, otherwise, may not be feasible. ${ }^{13-16}$ These simulations unexpectedly reveal the existence of a unique non-covalent bonding that holds $\mathrm{HIO}_{3}$ or $\mathrm{HIO}_{2}$ and $\mathrm{IONO}_{2}$ together at the air-water interface, preventing iodide formation. This is the first time that such non-covalent bonding in the context of atmospheric chemistry has been studied in an aqueous environment via molecular simulations. Finally, we present gas-phase ab initio calculations to provide deeper insights into the non-covalent $\mathrm{HIO}_{3}-\mathrm{IONO}_{2}$ and $\mathrm{HIO}_{2}-$ $\mathrm{IONO}_{2}$ bonding.

Computational Methods. BOMD simulations were performed based on DFT implemented in the $\mathrm{CP}_{2} \mathrm{~K}^{17}$ code. In the BOMD simulations, the droplet system contained 191 water molecules and one $\mathrm{HIO}_{3}$ or $\mathrm{HIO}_{2}$ molecule and one $\mathrm{IONO}_{2}$. The dimensions of the simulation box were $x=35 \AA ⿻, y=35 \AA$, and $z=35 \AA$, making the box large enough to avoid interactions between adjacent periodic images of the water droplet. Both types of chemistries $\left(\mathrm{HIO}_{3}-\mathrm{IONO}_{2}\right.$ and $\mathrm{HIO}_{2}-$ $\mathrm{IONO}_{2}$ ) at the air-water interface were explored by setting up fifteen different simulations for each case. The orientation of $\mathrm{HIO}_{3}-\mathrm{IONO}_{2}$ and $\mathrm{HIO}_{2}-\mathrm{IONO}_{2}$ with respect to the center of the droplet as well as the intermolecular distance between $\mathrm{HIO}_{3}$ or $\mathrm{HIO}_{2}$ and $\mathrm{IONO}_{2}$ were altered to set up these simulations. The starting configurations of the interface-bound $\mathrm{HIO}_{3}-\mathrm{IONO}_{2}$ and $\mathrm{HIO}_{2}$ $\mathrm{IONO}_{2}$ complexes are shown in Figures S1-S3. Prior to the BOMD simulations, the system was fully relaxed using DFT, in which the exchange and correlation interaction was treated with the Perdew, Burke, and Ernzerhof (PBE) exchange-correlation functional. ${ }^{18,19}$ Grimme's dispersion correction $\left(D_{3}\right)$ was applied to account for the weak dispersion interaction. ${ }^{20,21}$ A double- $\zeta$ Gaussian basis set combined with an auxiliary basis set and Goedecker-Teter-Hutter (GTH) norm-conserved pseudopotentials were adopted to treat the valence electrons and core electrons, respectively. ${ }^{22,23}$ An energy cutoff of 280 Rydberg was set for the plane-wave basis set, and a cutoff of 40 Rydberg was set for the Gaussian basis set. The BOMD simulations were carried out in the constant volume and temperature (NVT) ensemble, using the Nose-Hoover chain method to control the temperature (300 K) of the system. The integration step was set as 1 $\mathrm{fs}$, which has been proven to achieve sufficient energy conservation in water systems. ${ }^{9,15,16}$ Both systems were simulated for 40 picoseconds (ps).
All gas-phase quantum mechanical calculations reported in this work were performed using the Gaussiano $9^{24}$ software at standard temperature $(298.15 \mathrm{~K})$ and pressure (1 atm). Both $\mathrm{HIO}_{3}-\mathrm{IONO}_{2}$ and $\mathrm{HIO}_{2}-\mathrm{IONO}_{2}$, complexes as well as their deprotonated forms were explored in the gas phase. The gas-phase geometries of all stationary points on the potential energy surfaces of both reactions were first fully optimized using the Mo6$2 \mathrm{X}^{25}$ density functional theory (DFT) method and augcc-pVDZ ${ }^{26,27}$ basis set for $\mathrm{H}$ and $\mathrm{O}$, and effective core potential LANL2DZ basis set for Iodine atoms (Mo62X/aug-cc-pVDZ+LANL2DZ), and subsequent normalmode vibrational frequency analyses were performed to confirm that the stable minima had all positive vibrational frequencies. The electronic binding energies and Gibbs free energies of the gas-phase complexes were further refined using the coupled-cluster single and double substitution method with a perturbative treatment of triple excitations $(\operatorname{CCSD}(\mathrm{T}))^{28}$ and the aug-ccpVTZ+LANL2DZ basis set. For all reactions, the Mo62X/aug-cc-pVDZ+LANL2DZ calculated unscaled vibrational frequencies were used to estimate the zero-point energy corrections. In addition, the natural bond orbital (NBO) analysis of these complexes was also performed. The electrostatic potential maps of individual entities involved in these complexes were also calculated at the Mo6-2X/aug-cc-pVDZ+LANL2DZ level of theory. The IR spectral analysis of $\mathrm{HIO}_{3}-\mathrm{IONO}_{2}$ and $\mathrm{HIO}_{2}-\mathrm{IONO}_{2}$ complexes were also performed at the Mo6-2X/aug-ccpVDZ+LANL2DZ and MP2/aug-cc-pVDZ+LANL2DZ levels of theory. In addition to the above-mentioned iodine complexes, we have also analyzed the electrostatic potential maps of $\mathrm{I}_{2} \mathrm{O}_{2}$ and $\mathrm{I}_{2} \mathrm{O}_{3}$ here.

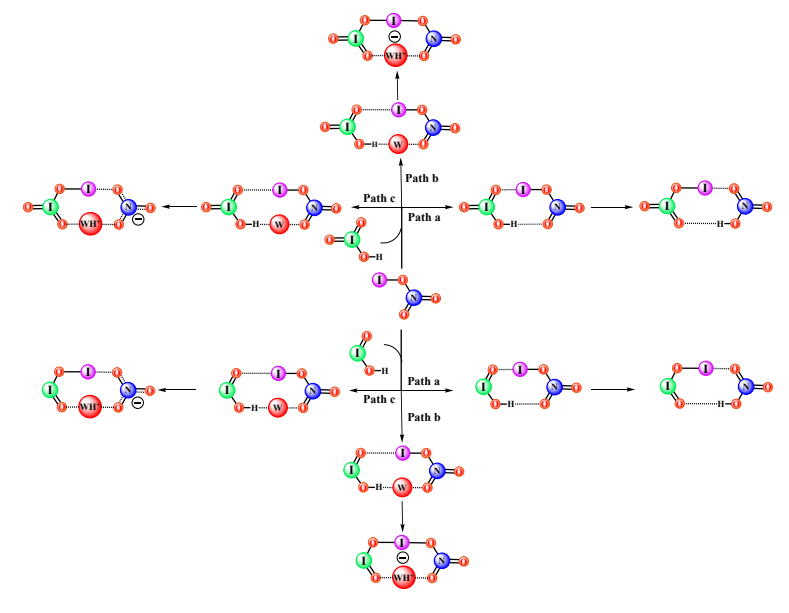

Scheme 1. Plausible reaction paths resulting from the interaction of $\mathrm{HIO}_{3}$ and $\mathrm{HIO}_{2}$ with $\mathrm{IONO}_{2}$. 


\section{Results and Discussion.}

a) Air-Water interface inclusive BOMD simulations. We studied the $\mathrm{HIO}_{2}-\mathrm{IONO}_{2}$ and $\mathrm{HIO}_{3}-$ $\mathrm{IONO}_{2}$ interactions at the air-water interface to investigate if the formation of $\mathrm{I}_{2} \mathrm{O}_{\mathrm{y}}(\mathrm{y}=2,3)$ and nitric acid $\left(\mathrm{HNO}_{3}\right)$ from these reactions could be observed. These bi-molecular paths were not observed in any of our simulations. Surprisingly, these interactions lead to the formation of an unusual kind of bonding between $\mathrm{HIO}_{3}$ or $\mathrm{HIO}_{2}$ and $\mathrm{IONO}_{2}$ (Scheme 1), i.e., a halogen bond is formed, in which the iodine atom attached to $\mathrm{IONO}_{2}$ behaves like a proton and resides nearly equidistant from $\mathrm{HIO}_{3}$ or $\mathrm{HIO}_{2}$ and $\mathrm{IONO}_{2}$. This halogen bonding is quite similar to hydrogen bonding except for the fact that the iodine atom in $\mathrm{IONO}_{2}$ behaves like a proton, i.e., iodinium ion, which holds together interacting species. It is important to mention here that though the halogen bonding involving $\mathrm{HIO}_{3}$ in the gas-phase has been previously discussed in literature, ${ }^{29}$ this is the first time such interactions are predicted to be feasible in an interfacial environment. The simulation results suggest that the $\mathrm{IONO}_{2}$-induced halogen bonding is quite strong, since it remains intact over the course of the simulated time scale of $40 \mathrm{ps}$. There are important

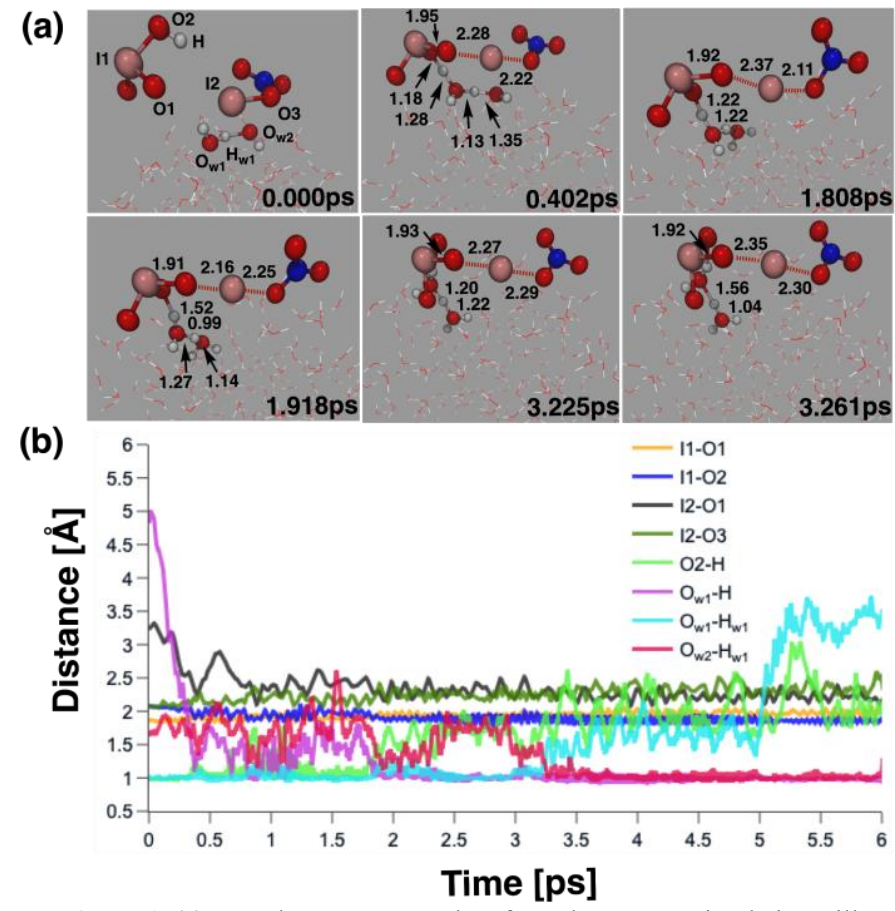

Figure 1. (a) Snapshot structures taken from the BOMD simulations, illustrating the halogen bond formation between $\mathrm{HIO}_{3}$ and $\mathrm{IONO}_{2}$ at the airwater interface represented by a water droplet of 191 water molecules. The topmost panel shows the atom numbering used in the discussion of BOMD simulation results. (b) Time evolution of key bond distances involved in the $\mathrm{HIO}_{3}-\mathrm{IONO}_{2}$ interaction en route to halogen bond formation. This figure describes the dominant mechanistic channel that leads to halogen bond formation between $\mathrm{HIO}_{3}$ and $\mathrm{IONO}_{2}$ at the air-water interface. mechanistic distinctions between the $\mathrm{HIO}_{3}-\mathrm{IONO}_{2}$ and $\mathrm{HIO}_{2}-\mathrm{IONO}_{2}$ interactions at the air-water interface. For example, the halogen bond formation in the $\mathrm{HIO}_{3}$ $\mathrm{IONO}_{2}$ reaction is accompanied by the deprotonation of $\mathrm{HIO}_{3}$, i.e., [OOI-O $\cdots\left[\mathrm{I} \cdot \mathrm{ONO}_{2}\right]^{-}$, whereas no such deprotonation occurs during the $\mathrm{HIO}_{2}-\mathrm{IONO}_{2}$ reaction ([HO$\left.\mathrm{I}-\mathrm{O} \cdots\left[-\ldots \mathrm{ONO}_{2}\right]\right)$. A more detailed description of the $\mathrm{HIO}_{3}-\mathrm{IONO}_{2}$ and $\mathrm{HIO}_{2}-\mathrm{IONO}_{2}$ interactions at the airwater interface is provided below.

b) $\mathrm{HIO}_{3}-\mathrm{IONO}_{2}$ interaction at the air-water interface. Ten different simulations were set up to study the $\mathrm{HIO}_{3}-\mathrm{IONO}_{2}$ interaction at the air-water interface. In all of simulations, the formation of halogen bonding is observed followed by deprotonation of $\mathrm{HIO}_{3}$. Importantly, two different channels were observed: (i) the oxygen atom in $\mathrm{HIO}_{3}$, which participates in halogen bonding, is different from the one undergoing deprotonation, and (ii) the oxygen atom in $\mathrm{HIO}_{3}$, which undergoes deprotonation, also participates in halogen bonding. The former mechanistic channel is the dominant one with $80 \%$ probability (Figure 1 and Movie S1) whereas the latter one is a minor channel with a probability of $\mathbf{2 0} \%$ (Figure 2 and Movie S2).

In the dominant channel (Figure 1), initially $\mathrm{HIO}_{3}$ and $\mathrm{IONO}_{2}$ are appreciably separated as indicated by the $\mathrm{I}_{2}-\mathrm{O}_{1}$ bond distance of $3.25 \AA$ at $0.000 \mathrm{ps}$. At this point, $\mathrm{I}_{2}-\mathrm{O}_{3}$ bond is quite strong, i.e., $\mathrm{I}_{2}-\mathrm{O}_{3}=2.07 \AA$. There is also hardly any interaction between $\mathrm{HIO}_{3}$ and the interfacial water molecule, i.e., $\mathrm{O}_{w_{1}-}-\mathrm{H}=5.00 \AA$ at o.ooo ps. The interactions involving $\mathrm{HIO}_{3}, \mathrm{IONO}_{2}$ and interfacial water molecules start developing very quickly. At $0.402 \mathrm{ps}$, the $\mathrm{I}_{2}-\mathrm{O}_{3}$ bond is noticeably elongated to $2.22 \AA$. More importantly, $\mathrm{HIO}_{3}$ and $\mathrm{IONO}_{2}$ also come closer, which is indicated by a tighter $\mathrm{I}_{2}-\mathrm{O} 1$ bond distance of $2.28 \AA$. At this point, the I 2 starts behaving like a proton and forms an unusual interaction with $\mathrm{HIO}_{3}$, which is described as halogen bonding (HO-OI$\mathrm{O} \cdots\left[. . . \mathrm{ONO}_{2}\right)$. We have also performed bonding and structural analysis of $\mathrm{HIO}_{3}-\mathrm{IONO}_{2}, \mathrm{IO}_{3}-\mathrm{IONO}_{2}, \mathrm{HIO}_{2}-$ $\mathrm{IONO}_{2}$ and $\mathrm{IO}_{2}-\mathrm{IONO}_{2}$ complexes in the gas-phase, which further supports our viewpoint about this interaction being a halogen bond. This will be discussed in greater detail in the next section. Until this point, the neutral $\mathrm{HIO}_{3}$ participates in the halogen bond formation. But beyond that, $\mathrm{HIO}_{3}$ starts deprotonating by losing its proton to the nearby water molecule. The transition state-like complex for this proton transfer step is formed at $1.808 \mathrm{ps}$, i.e., both $\mathrm{O}_{2}-\mathrm{H}$ and $\mathrm{O}_{w_{1}}-\mathrm{H}$ bonds are equidistant at $1.22 \AA$, respectively. The proton transfer is deemed complete at 1.918 ps, which is indicated by $\mathrm{O}_{2}-\mathrm{H}$ and $\mathrm{O}_{w_{1}}-\mathrm{H}$ bond distances of 1.52 and $0.99 \AA$, respectively. After this proton transfer, the [OOI-O $\cdots\left[\ldots \mathrm{ONO}_{2}\right]^{-}$complex is formed, in which the halogen bond $(\mathrm{O} \cdots \mathrm{I} \cdots \mathrm{O})$ remains fairly stable and keeps the deprotonated $\mathrm{HIO}_{3}$ and $\mathrm{IONO}_{2}$ tightly bound over the 

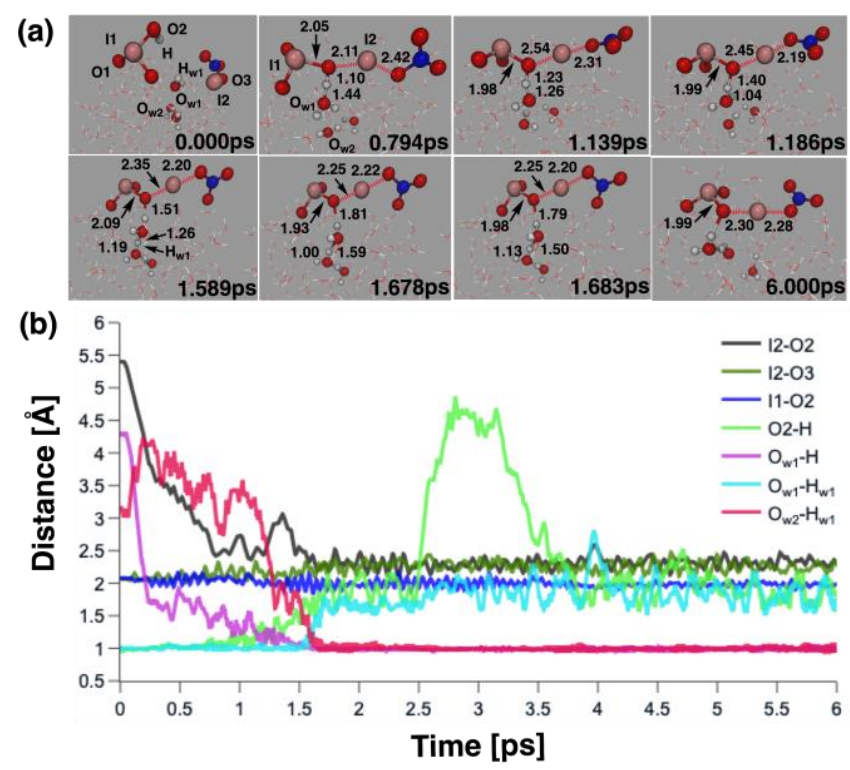

Figure 2. (a) Snapshot structures taken from the BOMD simulations, illustrating the halogen bond formation between $\mathrm{HIO}_{3}$ and $\mathrm{IONO}_{2}$ at the airwater interface represented by a water droplet of 191 water molecules. The topmost panel shows the atom numbering used in the discussion of BOMD simulation results. (b) Time evolution of key bond distances involved in the $\mathrm{HIO}_{3}-\mathrm{IONO}_{2}$ interaction en route to halogen bond formation. This figure describes the minor mechanistic channel that leads to halogen bond formation between $\mathrm{HIO}_{3}$ and $\mathrm{IONO}_{2}$ at the air-water interface.

simulated time scale. This proton transfer also leads to the formation of the interfacial hydronium ion, which subsequently loses one of its protons to the nearby water molecule. The transition state-like complex for that proton transfer is formed at $3.225 \mathrm{ps}$, in which the $\mathrm{O}_{\mathrm{w1}_{1}}$ $\mathrm{H}_{\mathrm{w} 1}$ and $\mathrm{O}_{\mathrm{w}_{2}}-\mathrm{H}_{\mathrm{w} 1}$ bond distances are 1.20 and $1.22 \AA$, respectively. This proton transfer is completed at $3.261 \mathrm{ps}$ when the $\mathrm{O}_{\mathrm{w}_{1}}-\mathrm{H}_{\mathrm{w} 1}$ bond is $1.56 \AA$ long whereas the $\mathrm{O}_{\mathrm{w}_{2}}-$ $\mathrm{H}_{\mathrm{w} 1}$ bond is $1.04 \AA$ long. At this time, the $\mathrm{I}_{2}-\mathrm{O}_{3}$ bond is 2.30 A long and the I2-O1 bond is $2.35 \AA$ A long. Beyond this point, the halogen bond remains stable as indicated by the time evolution profiles of key bond distances (Figure 1 and Figure $\mathbf{S}_{4}$ ).

The minor channel involved in the $\mathrm{HIO}_{3}$ $\mathrm{IONO}_{2}$ halogen bond formation is described in Figure 2 and Movie S2. As mentioned earlier, this channel leads to the formation of the $\left[\mathrm{O}-\mathrm{OI}-\mathrm{O} \cdot \ldots\left[\mathrm{I} \cdot \mathrm{ONO}_{2}\right]^{-} \mathrm{com}-\right.$ plex, but via a different mechanism, i.e., the oxygen atom of $\mathrm{HIO}_{3}$, which forms halogen bond with $\mathrm{IONO}_{2}$, also undergoes deprotonation to nearby interfacial water molecule. At $0.000 \mathrm{ps}$, there is hardly any interaction between $\mathrm{O}_{2}$ of $\mathrm{HIO}_{3}$ and $\mathrm{I}_{2}$ of $\mathrm{IONO}_{2}$ as indicated by the $\mathrm{I}_{2}-\mathrm{O}_{2}$ bond distance of $5.40 \AA$. At this point, the $\mathrm{I}_{2}-\mathrm{O}_{3}$ bond is quite stable, i.e., $\mathrm{I}_{2}-\mathrm{O}_{3}=2.07 \AA$. Beyond this point, the $\mathrm{I}_{2}-\mathrm{O}_{3}$ bond starts elongating and the interaction between $\mathrm{I}_{2}$ and $\mathrm{HIO}_{3}$ also starts developing. At $0.794 \mathrm{ps}$, the $\mathrm{I}_{2}-\mathrm{O}_{3}$ bond is elongated to $2.42 \AA$, which represents a significant increase in the bond distance compared to the original value of $2.07 \AA$. Simultaneously, the $\mathrm{I}_{2}-\mathrm{O}_{2}$ bond distance is also significantly reduced from $5.40 \AA$ to $2.11 \AA$, indicating the formation of a halogen bond between $\mathrm{HIO}_{3}$ and $\mathrm{IONO}_{2}$ ([O$\left.\mathrm{OI}(\mathrm{HO}) \cdots\left[\mathrm{I} \cdot \mathrm{ONO}_{2}\right]\right)$. The $\mathrm{I}_{1}-\mathrm{O}_{2}$ bond $(2.05 \AA)$ is quite stable at this point. The next step involves the deprotonation of $\mathrm{O}_{2}$ from the $\left(\mathrm{O}-\mathrm{OI}(\mathrm{HO}) \cdots\left[\mathrm{I} \cdot \mathrm{ONO}_{2}\right.\right.$ complex to the $\mathrm{O}_{\mathrm{w} 1}$ of the air-water interface. The transition statelike complex for this deprotonation is formed at $1.139 \mathrm{ps,}$ in which the $\mathrm{O}_{2}-\mathrm{H}$ bond is $1.23 \AA$ long whereas the $\mathrm{O}_{\mathrm{w1}}-$ $\mathrm{H}$ bond is $1.26 \AA$ long. The $\mathrm{I}_{2}-\mathrm{O}_{2}$ bond is $2.54 \AA$ long and the $\mathrm{I}_{2}-\mathrm{O}_{3}$ bond is $2.31 \AA$ A long. The deprotonation is considered complete at $1.186 \mathrm{ps}$ when the $\mathrm{O}_{2}-\mathrm{H}$ bond is 1.40 $\AA$ long and the $\mathrm{O}_{w_{1}}-\mathrm{H}$ bond is $1.04 \AA$ long. This deprotonation results in the formation of the [O-OI$\mathrm{O} \cdots\left[. . . \mathrm{ONO}_{2}\right]^{-}$complex and the interfacial hydronium ion, which subsequently undergoes deprotonation to the nearby water molecule $\left(\mathrm{O}_{\mathrm{w}_{2}}\right)$. The transition statelike complex for this deprotonation is formed at 1.589 ps, in which the $\mathrm{O}_{w_{1}}-\mathrm{H}_{w_{1}}$ bond is $1.26 \AA$ and $\mathrm{O}_{w_{2}}-\mathrm{H}_{\mathrm{w} 1}$ bond is $1.19 \AA$ A long. This deprotonation is completed at 1.678 ps as indicated by the $\mathrm{O}_{w_{1}}-\mathrm{H}_{\mathrm{w}_{1}}$ and $\mathrm{O}_{\mathrm{w}_{2}}-\mathrm{H}_{\mathrm{w} 1}$ bond distances of 1.59 and $1.00 \AA$, respectively. At this point, the $\mathrm{I}_{2}-\mathrm{O}_{2}$ bond is $2.25 \AA$ long and the $\mathrm{I}_{2}-\mathrm{O}_{3}$ bond is $\mathbf{2 . 2 2}$ $\AA$ long. Beyond this point, the halogen bond remains fairly stable as indicated by the time evolution profiles of key bond distances (Figure 2 and Figure $\mathrm{S}_{5}$ ). For example, the $\mathrm{I}_{2}-\mathrm{O}_{2}$ bond is $2.25 \AA$ long and the $\mathrm{I}_{2}-\mathrm{O}_{3}$ bond is $2.20 \AA$ long at 1.683 ps. At $6.000 \mathrm{ps}$, the $\mathrm{I}_{2}-\mathrm{O}_{2}$ bond is 2.30 $\AA$ long and the $\mathrm{I}_{2}-\mathrm{O}_{3}$ bond is $2.28 \AA$ long.

It is important to mention here that the deprotonation of $\mathrm{IONO}_{2}$-bound $\mathrm{HIO}_{3}$ at the air-water interface does not occur due to the presence of $\mathrm{IONO}_{2}$, but it is due to the fact that $\mathrm{HIO}_{3}$ is a relatively stronger acid with pKa value of $0.78,3^{30}$ which tends to lose a proton in the presence of appropriate proton acceptors. We have run additional BOMD simulations to investigate the dynamics of $\mathrm{HIO}_{3}$ at the air-water interface (Movie $\mathbf{S}_{3}$ ). The results suggest that $\mathrm{HIO}_{3}$ at the air-water interface deprotonates within a couple of ps, which support the viewpoint that $\mathrm{HIO}_{3}$ behaves as a stronger acid at the air-water interface. Since the $\mathrm{HIO}_{3}$ deprotonation occurs very fast, we have not run $\mathrm{HIO}_{3}$ simulations beyond 5 ps.

c) $\mathrm{HIO}_{2}-\mathrm{IONO}_{2}$ interaction at the air-water interface. The simulation results show that $\mathrm{HIO}_{2}$ also forms halogen bonding with $\mathrm{IONO}_{2}$. As for the $\mathrm{HIO}_{3}$ $\mathrm{IONO}_{2}$ ten different simulations were run to probe the $\mathrm{HIO}_{2}-\mathrm{IONO}_{2}$ interaction. The simulation data suggests that there is only one mechanistic involved in the halogen bond formation between $\mathrm{HIO}_{2}$ and $\mathrm{IONO}_{2}$. Unlike $\mathrm{HIO}_{3}, \mathrm{HIO}_{2}$ does not lose its proton to the nearby water molecules en route to the halogen bond formation, i.e., the $\left[\mathrm{HOI}-\mathrm{O} \cdots\left[\mathrm{m} \cdot \mathrm{ONO}_{2}\right]\right.$ complex is formed from the $\mathrm{HIO}_{2}-\mathrm{IONO}_{2}$ interaction whereas $\left[\mathrm{O}-\mathrm{OI}-\mathrm{O} \cdots\left[\mathrm{\cdots} \cdot \mathrm{ONO}_{2}\right]^{-}\right.$ 
(a)

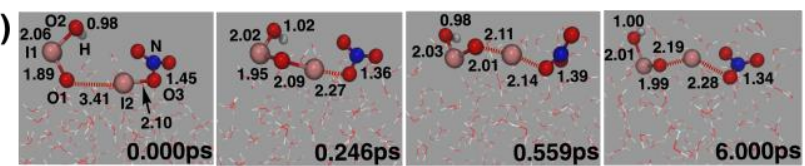

(b)

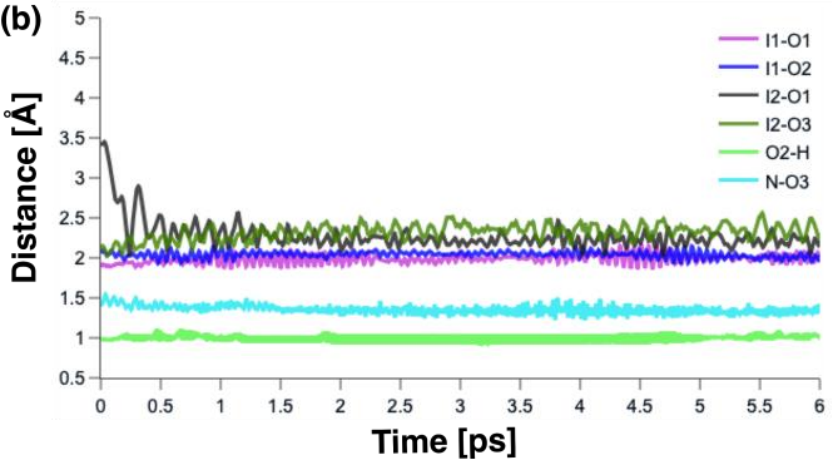

Figure 3. (a) Snapshot structures taken from the BOMD simulations, illustrating the halogen bond formation between $\mathrm{HIO}_{2}$ and $\mathrm{IONO}_{2}$ at the airwater interface represented by a water droplet of 191 water molecules. The topmost panel shows the atom numbering used in the discussion of BOMD simulation results. (b) Time evolution of key bond distances involved in the $\mathrm{HIO}_{2}-\mathrm{IONO}_{2}$ interaction en route to halogen bond formation.

complex is formed from the $\mathrm{HIO}_{3}-\mathrm{IONO}_{2}$ interaction at the air-water interface (Figure 3 and Movie $\mathbf{S}_{4}$ ). The halogen bonding between $\mathrm{HIO}_{2}$ and $\mathrm{IONO}_{2}$ is formed within a few picoseconds, which remains intact over the course of simulated time scale of 40 ps (Figure S6). As far as the mechanistic details of the $\mathrm{HIO}_{2}-\mathrm{IONO}_{2}$ interaction are concerned, both $\mathrm{HIO}_{2}$ and $\mathrm{IONO}_{2}$ are relatively farther at the start of simulations, which is evidenced by the I2-O1 bond distance of 3.41 Å. The halogen bond between $\mathrm{HIO}_{2}$ and $\mathrm{IONO}_{2}$ starts developing immediately, i.e., the iodine atom in $\mathrm{IONO}_{2}$ starts detaching from $\mathrm{IONO}_{2}$ and simultaneously starts forming bonding with $\mathrm{HIO}_{2}$. At $0.246 \mathrm{ps}$, the formation of halogen bond between $\mathrm{HIO}_{2}$ and $\mathrm{IONO}_{2}$ is deemed complete as indicated by the $\mathrm{I}_{2}-\mathrm{O}_{1}$ and $\mathrm{I}_{2}-\mathrm{O}_{3}$ bond distances of 2.09 and $2.27 \AA$, respectively. After some fluctuations, the halogen bonding remains intact. For example, at $0.559 \mathrm{ps}$, the $\mathrm{I}_{2}-\mathrm{O}_{1}$ and $\mathrm{I}_{2}-\mathrm{O}_{3}$ bond distances are 2.01 and $2.14 \AA$ long whereas at $6.000 \mathrm{ps}$, these bonds are 2.19 and $2.28 \AA$ A long, respectively.

d) Combined distribution plot analysis. We next calculated the combined distribution functions (CDFs) for the $\mathrm{HIO}_{3}-\mathrm{IONO}_{2}$ and $\mathrm{HIO}_{2}-\mathrm{IONO}_{2}$ complexes at the air-water interface by combining a radial distribution function (RDF) between the iodine atom of $\mathrm{IONO}_{2}\left(\mathrm{I}_{2}\right)$ and the $\mathrm{O}$ atom of $\mathrm{HIO}_{3}\left(\mathrm{O} 1\right.$ or $\left.\mathrm{O}_{2}\right)$ or $\mathrm{HIO}_{2}$ $\left(\mathrm{O}_{1}\right)$ and an angular distribution function (ADF) between the $\mathrm{I}_{2} \cdot \mathrm{O}_{3}$ and $\mathrm{I}_{2} \cdot \cdot \mathrm{O}_{1}$ or $\mathrm{I}_{2} \cdot \mathrm{O}_{2}$ vectors (Figure 4a). These histograms of higher dimensionality provide further insight into the unusual $\mathrm{O} \cdot \cdot \mathrm{I}-\mathrm{O}$ halogen bonding in an aqueous environment. Using CDFs, we could define the $\mathrm{O} \cdot \mathrm{I}-\mathrm{O}$ halogen bonding criteria in the interfacial aqueous environment. Careful analysis of CDFs suggests that the halogen bonding between $\mathrm{I}_{2}$ of $\mathrm{IONO}_{2}$ and $\mathrm{O}_{1}$ of $\mathrm{HIO}_{3}$ could be characterized using a criterion with $2.05 \AA \leq \mathrm{I}_{2} \cdot \cdot \mathrm{O}_{1} \leq 2.35 \AA$ and $164^{\circ} \leq \theta\left(=\angle \mathrm{O}_{1} \cdot \cdot \mathrm{I}_{2}-\mathrm{O}_{3}\right) \leq$ $180^{\circ}$ whereas the halogen bonding between $\mathrm{I}_{2}$ of $\mathrm{IONO}_{2}$ and $\mathrm{O}_{2}$ of $\mathrm{HIO}_{3}$ could be characterized using a criterion with $2.10 \AA \leq \mathrm{I}_{2} \cdot \cdot \mathrm{O}_{2} \leq 2.40 \AA$ and $162^{\circ} \leq \theta\left(=\angle \mathrm{O}_{2} \cdot \cdot \mathrm{I}_{2}-\mathrm{O}_{3}\right) \leq$ $180^{\circ}$. The peak for the $\mathrm{I}_{2} \cdot \cdot \mathrm{O}_{1}$ distance distribution in the $\mathrm{O}_{1} \cdot \cdot \mathrm{I}_{2}-\mathrm{O}_{3}$ halogen bonding occurs at $2.20 \AA$ and the corresponding peak for the $\mathrm{O}_{1} \cdot \mathrm{I}_{2}-\mathrm{O}_{3}$ angle distribution occurs at $178^{\circ}$. The peak for the $\mathrm{I}_{2} \cdot \mathrm{O}_{2}$ distance distribution in the $\mathrm{O}_{2} \cdot \cdot \mathrm{I}_{2}-\mathrm{O}_{3}$ halogen bonding occurs at $2.25 \AA$ and the corresponding peak for the $\mathrm{O}_{2} \cdot \mathrm{I}_{2}-\mathrm{O}_{3}$ angle distribution occurs at $174^{\circ}$. This suggests that the halogen bonding in the latter case is slightly weaker, which may be due to the fact that the $\mathrm{O}_{2}$ of $\mathrm{HIO}_{3}$ is initially directed away from $\mathrm{I}_{2}$ of $\mathrm{IONO}_{2}$ and has to reorganize to induce $\mathrm{I}_{2} \cdot \mathrm{O}_{2}$ halogen bonding. Interestingly, the halogen bonding between $\mathrm{I}_{2}$ of $\mathrm{IONO}_{2}$ and $\mathrm{O}_{1}$ of $\mathrm{HIO}_{2}$ follows structural criteria which is very similar to the one between $\mathrm{I}_{2}$ of $\mathrm{IONO}_{2}$ and $\mathrm{O}_{1}$ of $\mathrm{HIO}_{3}$. The peak for the $\mathrm{I}_{2} \cdot \mathrm{O}_{1}$ distance distribution in the $\mathrm{O}_{1} \cdot \mathrm{I}_{2}-\mathrm{O}_{3}$ halogen bonding in the $\mathrm{HIO}_{2}-\mathrm{IONO}_{2}$ occurs at $2.19 \AA$ and the corresponding peak for the $\mathrm{O}_{1} \cdot \mathrm{I}_{2}-\mathrm{O}_{3}$ angle distribution occurs at $178^{\circ}$. The CDFs of two RDFs involving $\mathrm{I}_{2} \cdot \cdot \mathrm{O} 1$ and $\mathrm{I}_{2} \cdot \cdot \mathrm{O}_{3}$ bond distances in the $\mathrm{O}_{1} \cdot \cdot \mathrm{I}_{2}-\mathrm{O}_{3}$ halogen bonding in the $\mathrm{HIO}_{3}-\mathrm{IONO}_{2}$ complex at the air-water interface suggest that the peak for the I2..O1 distance distribution occurs at $\mathbf{2 . 2 2} \AA$ A whereas the corresponding peak for the $\mathrm{I}_{2} \cdot \mathrm{O}_{3}$ distance distribution occurs at 2.32 $\AA$ (Figure $4 \mathbf{b}$ ). For the $\mathrm{O}_{2} \cdot \cdot \mathrm{I}_{2}-\mathrm{O}_{3}$ halogen bonding in the $\mathrm{HIO}_{3}-\mathrm{IONO}_{2}$ complex, the peak for the $\mathrm{I}_{2} \cdot \mathrm{O}_{2}$ distance distribution occurs at $2.25 \AA$ whereas the corresponding peak for the $\mathrm{I}_{2} \cdot \cdot \mathrm{O}_{3}$ distance distribution occurs at 2.30 A. Similar peak for the $\mathrm{I}_{2} \cdot$. O1 distance distribution in the $\mathrm{HIO}_{2}-\mathrm{IONO}_{2}$ complex occurs at $2.19 \AA$
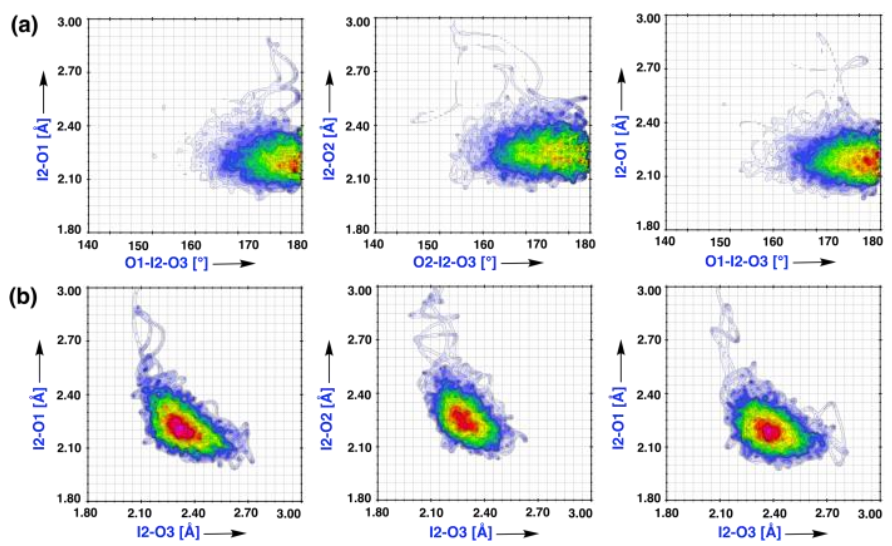

Figure 4. Combined radial/angular distribution function (CDF). The top panels show the CDFs involving a radial distribution function (RDF) between $\mathrm{I}_{2}$ of the $\mathrm{IONO}_{2}$ and $\mathrm{O}_{1}$ or $\mathrm{O}_{2}$ of $\mathrm{HIO}_{3}$ (two left most panels) and $\mathrm{O}_{1}$ of $\mathrm{HIO}_{2}$ (extreme right panel) at the air-water interface and an angular distribution function between the $\mathrm{I}_{2} \cdot \mathrm{O}_{3}$ and $\mathrm{I}_{2} \cdot . \mathrm{O} 1$ or $\mathrm{I}_{2} \cdot \mathrm{O}_{2}$ vectors. The lower panels show the CDFs involving a RDF between $\mathrm{I}_{2}$ and $\mathrm{O}_{3}$ of the $\mathrm{IONO}_{2}$ and a RDF between the $\mathrm{I}_{2}$ of $\mathrm{IONO}_{2}$ and $\mathrm{O}_{1}$ or $\mathrm{O}_{2}$ of $\mathrm{HIO}_{3}$ (two left most panels) and $\mathrm{O}_{1}$ of $\mathrm{HIO}_{2}$ (extreme right panel). 
(a)

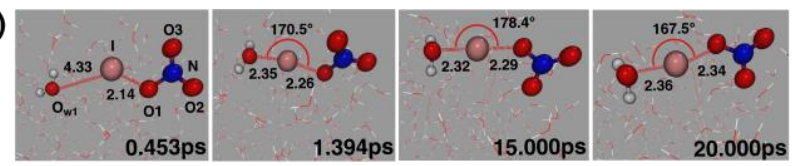

(b)

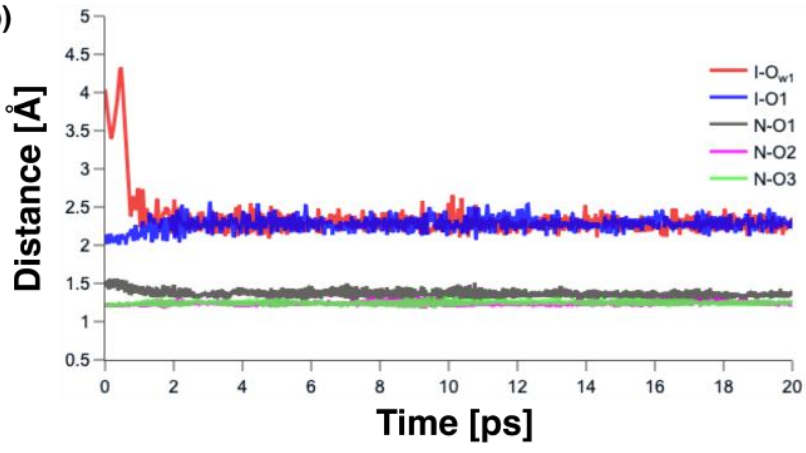

(c)

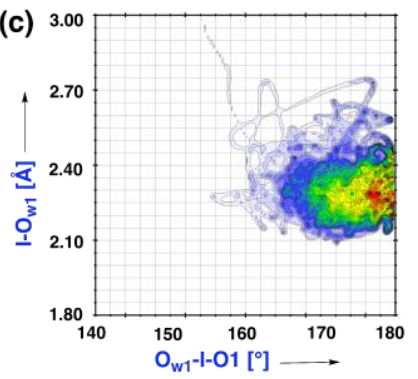

Figure 5. (a) Snapshot structures taken from the BOMD simulations, illustrating the halogen bond formation between $\mathrm{H}_{2} \mathrm{O}$ and $\mathrm{IONO}_{2}$ at the air-water interface. The topmost panel shows the atom numbering used in the discussion of BOMD simulation results. (b) Time evolution of key bond distances involved in the $\mathrm{H}_{2} \mathrm{O}-\mathrm{IONO}_{2}$ interaction en route to halogen bond formation. (c) $\mathrm{CDF}$ involving a radial distribution function (RDF) between I of the $\mathrm{IONO}_{2}$ and $\mathrm{Ow} 1$ of $\mathrm{H}_{2} \mathrm{O}$ and an $\mathrm{ADF}$ between the $\mathrm{I} \cdot \mathrm{OO} 1$ and $\mathrm{I} \cdot \cdot \mathrm{Ow} 1$ vectors. (d) CDF involving a RDF between I and $\mathrm{O} 1$ of the $\mathrm{IONO}_{2}$ and a RDF between the $\mathrm{I}$ of $\mathrm{IONO}_{2}$ and $\mathrm{Ow} 1$.

Whereas the corresponding peak for the $\mathrm{I}_{2} \cdot \mathrm{O}_{3}$ distance distribution occurs at $2.40 \AA$.

e) $\mathrm{IONO}_{2}$ dynamics at the air-water interface. We also probed the dynamics behavior of $\mathrm{IONO}_{2}$ alone at the air-water interface to investigate whether $\mathrm{IONO}_{2}$ could also form halogen bond with the interfacial water molecules $\left(\mathrm{O}_{\mathrm{w1}} \cdot \cdot \mathrm{I}-\mathrm{O} 1\right)$. As shown in Figure 5, the simulation results suggest that the $\mathrm{IONO}_{2}$-induced halogen bonding at the air-water interface is indeed possible, i.e., the interfacial water oxygen interacts with the iodine atom of $\mathrm{IONO}_{2}$. Though the gas-phase possibility of the halogen bonding between water and $\mathrm{IONO}_{2}$ has been previously discussed in literature, ${ }^{31}$ the present simulations suggest that the $\mathrm{IONO}_{2}-\mathrm{H}_{2} \mathrm{O}$-based halogen bonding may be formed on the aqueous surfaces that can have interesting implications for the iodine rich environments. As far as the time scale of the halogen bond formation is concerned, it occurs within a few ps. Initially, there is appreciable separation between the interfacial oxygen and iodine of $\mathrm{IONO}_{2}$. For example, the $\mathrm{I} \cdot \mathrm{O}_{\mathrm{w}_{1}}$ bond distance is $4.33 \AA \AA$ long at 0.453 ps (Figure 5a and $5 \mathbf{b})$. Beyond this point, the $\mathrm{I} \cdot \mathrm{O}_{\mathrm{w} 1}$ bond distances

starts dropping very fast, which is also accompanied by the simultaneous stretching of the I-O1 bond. This results in the formation of an $\mathrm{O}_{\mathrm{w}} \cdot \cdot \mathrm{I}-\mathrm{O} 1$ halogen bond at $1.394 \mathrm{ps}$, in which the $\mathrm{I} \cdot \mathrm{O}_{\mathrm{w}_{1}}$ bond is $2.35 \AA$ and the $\mathrm{I} \cdot . \mathrm{O}_{1}$ bond is $2.26 \AA$. The halogen bond angle $\left(\angle \mathrm{O}_{\mathrm{w} 1} \cdot \mathrm{I} \cdot \cdot \mathrm{O} 1\right)$ at this point is $170.5^{\circ}$. The near linearity of the $\mathrm{O}_{\mathrm{w1}} \cdot \mathrm{I} \cdot \cdot \mathrm{O} 1$ interaction further suggests it to be a halogen bond, which remains intact over the simulated time scale of 40 ps. For example, the $\angle \mathrm{O}_{\mathrm{w} 1} \cdot \mathrm{I} \cdot \mathrm{O}_{1}$ at $15 \mathrm{ps}$ is $178.4^{\circ}$, and the $\mathrm{I} \cdot \mathrm{O}_{\mathrm{w} 1}$ and $\mathrm{I}-\mathrm{O}_{1}$ bonds are 2.32 and $2.29 \AA$, respectively. Similarly, the $\angle \mathrm{O}_{\mathrm{w} 1} \cdot \mathrm{I} \cdot \mathrm{O}_{1}$ at $20 \mathrm{ps}$ is $167.5^{\circ}$, and the $\mathrm{I} \cdot \mathrm{O}_{\mathrm{w} 1}$ and $\mathrm{I}-\mathrm{O} 1$ bonds are 2.36 and $2.34 \AA$, respectively. The average I.. $\mathrm{O}_{\mathrm{w}_{1}}$ and $\mathrm{I}-\mathrm{O} 1$ bond distances over 40 ps time scale are $2.35 \AA$ and $2.27 \AA$, respectively. Among the $\mathrm{N}-\mathrm{O}$ bonds, the $\mathrm{N}-\mathrm{O} 1$ bond is the longest one with an average value of $1.37 \AA$. The $\mathrm{N}-\mathrm{O}_{2}$ and $\mathrm{N}-\mathrm{O}_{3}$ bond distances have average values of 1.24 and $1.25 \AA$, respectively.

We next analyzed CDFs of the interfaciallybound $\mathrm{IONO}_{2}$ to gain deeper insights into the $\mathrm{O}_{\mathrm{w}} \cdot \mathrm{I}-\mathrm{O} 1$ halogen bonding (Figures $5 \mathbf{c}$ and $\mathbf{5} \mathbf{d}$ ). Specifically, we analyzed a CDF combining an RDF between $\mathrm{I}_{\text {of }} \mathrm{IONO}_{2}$ and $\mathrm{O}_{\mathrm{w}_{1}}$ atom of $\mathrm{H}_{2} \mathrm{O}$ and an ADF between the $\mathrm{I} \cdot \mathrm{O}_{\mathrm{w}_{1}}$ and I.. O1 vectors. The halogen bonding between $\mathrm{I}$ of $\mathrm{IONO}_{2}$ and the interfacial water molecules could be characterized using a criterion with $2.10 \AA \leq \mathrm{I} \cdot . \mathrm{O} 1 \leq 2.50 \AA$ and $164^{\circ} \leq \theta\left(=\angle \mathrm{O}_{\mathrm{w} 1} \cdot \mathrm{I} \cdot \cdot \mathrm{O} 1\right) \leq 180^{\circ}$. The peak for the I..O1 distance distribution in the $\mathrm{O}_{\mathrm{w1}} \cdot \mathrm{I}-\mathrm{O} 1$ halogen bonding occurs at $2.27 \AA$ and the corresponding peak for the $\angle \mathrm{O}_{\mathrm{w} 1} \cdot \cdot \mathrm{I}-\mathrm{O} 1$ angle distribution occurs at $177^{\circ}$. The CDFs of two RDFs involving $\mathrm{I} \cdot \cdot \mathrm{O}_{1}$ and $\mathrm{I} \cdot \cdot \mathrm{O}_{\mathrm{w}_{1}}$ bond distances in the $\mathrm{O}_{\mathrm{w} 1} \cdot \mathrm{I} \cdot$.O $\mathrm{O}$ halogen bonding suggest that the peak for both the $\mathrm{I} \cdot \mathrm{O}_{\mathrm{w} 1}$ and $\mathrm{I} \cdot . \mathrm{O} 1$ distance distribution occurs at $2.27 \AA$ Å. These structural signatures are typical for a halogen bonding system..$^{3-33}$

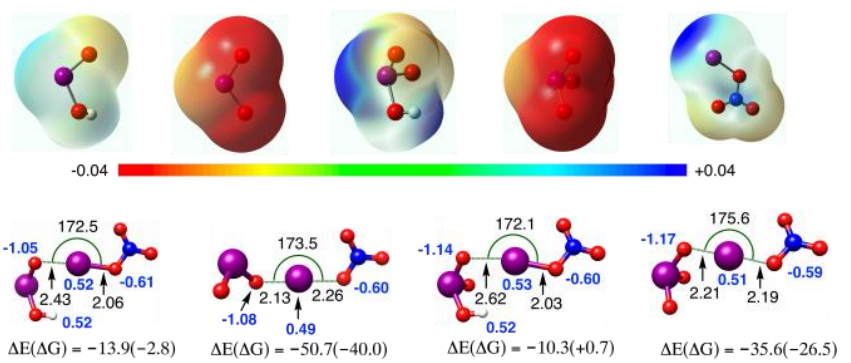

Figure 6. Upper panel: molecular electrostatic potential maps of $\mathrm{HIO}_{2}$, $\mathrm{IO}_{2}^{-}, \mathrm{HIO}_{3}, \mathrm{IO}_{3}{ }^{-}$, and $\mathrm{IONO}_{2}$. Red indicates negative electrostatic potential; blue refers to positive electrostatic potential. The electrostatic potential surfaces were calculated at an isovalue of 0.004. Lower panel: M06-2X/augcc-pVDZ+LANL2DZ optimized structures of $\mathrm{HIO}_{2}-\mathrm{IONO}_{2}, \mathrm{IO}_{2}{ }^{-} \mathrm{IONO}_{2}$, $\mathrm{HIO}_{3}-\mathrm{IONO}_{2}$ and $\mathrm{IO}_{3}{ }^{-}-\mathrm{IONO}_{2}$. Key bond distances and bond angles are shown. The calculated natural bond orbital (NBO) charges are also mentioned in blue color. See also Figure $\mathbf{S 7}$ for detailed NBO charge distribution. The CCSD(T)/aug-cc-pVTZ+LANL2DZ//M06-2X/aug-ccpVDZ+LANL2DZ calculated electronic binding energies of these complexes are also mentioned. Gibbs free energies are given in parentheses. Ball-stick representation was used for all structures. Iodine is shown in magenta, oxygen in red, nitrogen in blue, and hydrogen in white. 
f) Bonding and structural analysis in the gas-phase. To gain deeper insights into the $\mathrm{IONO}_{2}$-induced halogen bonding in $\mathrm{HIO}_{3}-\mathrm{IONO}_{2}$ and $\mathrm{HIO}_{2}-\mathrm{IONO}_{2}$ complexes, we next performed bonding and structural analysis of the $\mathrm{HIO}_{2}-\mathrm{IONO}_{2}, \mathrm{IO}_{2}-\mathrm{IONO}_{2}, \mathrm{HIO}_{3}-\mathrm{IONO}_{2}$ and $\mathrm{IO}_{3}-\mathrm{IONO}_{2}$ complexes in the gas-phase using Mo62X/aug-cc-pVDZ+LANL2DZ and MP2/aug-ccpVDZ+LANL2DZ levels of theory. The anionic complexes were also considered here because the BOMD simulations suggest that $\mathrm{HIO}_{3}$ at the air-water interface undergoes deprotonation and exists as $\mathrm{IO}_{3}{ }^{-}$while interacting with $\mathrm{IONO}_{2}$. As a first step, we calculated the molecular electrostatic potential surfaces of $\mathrm{HIO}_{2}, \mathrm{IO}_{2}{ }^{-}$, $\mathrm{HIO}_{3}, \quad \mathrm{IO}_{3}{ }^{-}, \quad \mathrm{IONO}_{2}$ at the Mo6-2X/aug-ccpVDZ+LANL2DZ level of theory (Figure 6). The Mo6$2 \mathrm{X}$ and MP2 calculated geometries are given in Tables S1 and S2, respectively. The calculations suggest that the electrostatic potential around the iodine atom of $\mathrm{IONO}_{2}$ is positively charged, which gives rise to the $\sigma$ hole, a typical signature of halogen bond donors. ${ }^{31-33}$ This explains why $\mathrm{IONO}_{2}$ acts as a halogen bond donor when interacting with $\mathrm{HIO}_{3}$ or $\mathrm{HIO}_{2}$. On the other hand, oxygens in $\mathrm{HIO}_{3}$ and $\mathrm{HIO}_{2}$ are negatively charged, which is significantly enhanced in their deprotonated forms. This suggests that deprotonated $\mathrm{HIO}_{3}$ and $\mathrm{HIO}_{2}$ will form stronger halogen bonds with $\mathrm{IONO}_{2}$. It is important to mention here that iodine atom in $\mathrm{HIO}_{3}$ and $\mathrm{HIO}_{2}$ also bear positive charges implying that both these iodine compounds can also act as halogen bond donors under appropriate conditions. However, we did not explore that mode of interaction in the gas-phase or at the air-water interface. Next we optimized the $\mathrm{HIO}_{2}$ $\mathrm{IONO}_{2}, \quad \mathrm{IO}_{2}^{-}-\mathrm{IONO}_{2}, \quad \mathrm{HIO}_{3}-\mathrm{IONO}_{2}$ and $\mathrm{IO}_{3}^{-}-\mathrm{IONO}_{2}$ complexes at the Mo6-2X/aug-cc-pVDZ+LANL2DZ level of theory and analyzed key structural parameters and NBO charges on key atoms in these complexes. The calculated halogen bond distances and their near linear nature is consistent with previous literature reports on halogen bonding..$^{32-34}$ The calculated NBO charges provide further insight into the $\mathrm{IONO}_{2}$-induced halogen bonding. In all the $\mathrm{IONO}_{2}$ complexes, iodine atom of $\mathrm{IONO}_{2}$ bears $\sim 0.5 \mathrm{O} \mathrm{NBO}$ charge indicating proton-like behavior. The oxygen atoms of $\mathrm{HIO}_{3}, \mathrm{HIO}_{2}, \mathrm{IO}_{3}{ }^{-}, \mathrm{IO}_{2}{ }^{-}$ and $\mathrm{IONO}_{2}$, which directly interact with the positively charged iodine of $\mathrm{IONO}_{2}$, bear negative charge. All the halogen bond acceptor oxygens bear nearly one-unit negative charge whereas the halogen bond donor oxygen of $\mathrm{IONO}_{2}$ bears nearly o.6o unit of negative charge. For a more detailed NBO picture in these complexes, see Figure $\mathbf{S}_{\mathbf{7}}$. The electronic binding energies of these complexes were next calculated at the $\operatorname{CCSD}(\mathrm{T}) /$ aug-ccpVTZ+LANL2DZ//Mo6-2X/aug-cc-pVDZ+LANL2DZ level of theory to investigate whether these halogen bonds are actually viable or not. See Table $\boldsymbol{S}_{\mathbf{3}}$ for more details. The calculations suggest that that the $\mathrm{IONO}_{2}-$ induced halogen bonds are quite stable in nature. The $\mathrm{HIO}_{2}-\mathrm{IONO}_{2}$ and $\mathrm{HIO}_{3}$ -
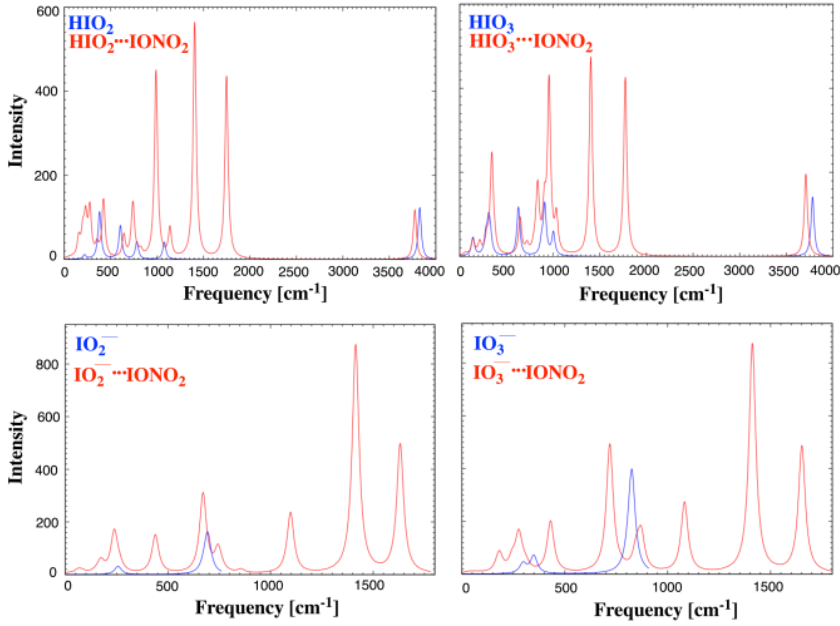

Figure 7. The M06-2X/aug-cc-pVDZ+LANL2DZ calculated IR spectra of free $\mathrm{HIO}_{2}, \mathrm{IO}_{2}{ }^{-}, \mathrm{HIO}_{3}$ and $\mathrm{IO}_{3}{ }^{-}$as well as their $\mathrm{IONO}_{2}$ complexes. The blue and red curves represent the spectra of iodine species before and after complexation, respectively. See also Table S1.

$\mathrm{IONO}_{2}$ complexes have 13.9 and $10.3 \mathrm{kcal} / \mathrm{mol}$ electronic binding energies, respectively. $\mathrm{HIO}_{3}$ and $\mathrm{HIO}_{2}$ could undergo deprotonation and give rise to the $\mathrm{IO}_{2}{ }^{-}-\mathrm{IONO}_{2}$ and $\mathrm{IO}_{3}{ }^{-}-\mathrm{IONO}_{2}$ complexes in the troposphere. The calculated binding energy of the $\mathrm{IO}_{2}^{-}-\mathrm{IONO}_{2}$ complex is $50.7 \mathrm{kcal} / \mathrm{mol}$ whereas that of the $\mathrm{IO}_{3}{ }^{-}-\mathrm{IONO}_{2}$ complex is $35.6 \mathrm{kcal} / \mathrm{mol}$. Clearly, the deprotonation of iodine acids could lead to stronger halogen bonding interactions. This gas-phase analysis suggests that the $\mathrm{IONO}_{2}-$ induced halogen bonding observed at the air-water interface is indeed possible.

We next analyzed harmonic vibrational frequencies to better understand the bonding structure of iodine species upon complexation. These frequencies were calculated at the Mo6-2X/aug-cc-pVDZ+ LANL2DZ and MP2/aug-cc-pVDZ+LANL2DZ levels of theory. Table $\mathbf{S}_{4}$ lists the calculated harmonic frequencies whereas Figure $\mathbf{S 8}$ shows the labeling scheme used in the discussion of frequency results. The Mo6-2X calculated spectra is shown in Figure 7 whereas the MP2 calculated spectra is shown in Figure S9. See Tables S2$S_{3}$ for the Mo6-2X- and MP2-optimized geometries of all species studied here. Results from both methods show that all species are global minima on their potential energy surface. Inspection of Table $\mathbf{S}_{4}$ reveals that the $\mathrm{I}_{1} \mathrm{O}_{2}$ bond length in free $\mathrm{HIO}_{2}$ and $\mathrm{HIO}_{3}$ were predicted to be 1.8036 and $1.7476 \AA$ respectively. These distances were increased by $0.02 \AA$ upon complexation. The IO bond distance in $\mathrm{IONO}_{2}(2.2556 \AA)$ also increased by $0.2 \AA$ upon complexation. The $\mathrm{I}_{1} \mathrm{O}_{2}$ distance in the $\mathrm{IO}_{2}{ }^{-}$was predicted to be $1.8653 \AA$, which increased by $0.044 \AA$ upon complexation. Similarly, the calculated $\mathrm{I}_{1} \mathrm{O}_{2}$ distance in $\mathrm{IO}_{3}^{-}$was $1.7838 \AA$, which increased by $0.058 \AA$ A upon complexation. The $\mathrm{I}_{1} \mathrm{O}_{3}$ and $\mathrm{I}_{1} \mathrm{O}_{4}$ distances 
in the $\mathrm{IO}_{3}{ }^{-}-\mathrm{IONO}_{2}$ complex did not change much relative to their value in free $\mathrm{IO}_{3}{ }^{-}$. This change in the equilibrium geometries will affect the harmonic frequencies. The $\mathrm{I}_{1} \mathrm{O}_{2}$ bond elongation results in redshift in the frequencies (Figure 7). For instance, the calculated $\mathrm{I}_{1} \mathrm{O}_{2}$ stretching mode in free $\mathrm{HIO}_{3}$ and $\mathrm{HIO}_{2}$ were 877 and 782 $\mathrm{cm}^{-1}$, respectively. These were redshifted by $41 \mathrm{~cm}^{-1}$ upon complexation. The $\mathrm{I}_{1} \mathrm{O}_{3}$ stretching mode does not change much and shows only a slight shift of $3 \mathrm{~cm}^{-1}$. The $\mathrm{I}_{1} \mathrm{O}_{2}$ stretching mode in $\mathrm{IO}_{3}^{-}-\mathrm{IONO}_{2}$ complex is redshifted by $108 \mathrm{~cm}^{-1}$, which is the largest redshift among all iodine complexes. Note that it is relatively harder to estimate the shift in the complexed $\mathrm{IO}_{2}{ }^{-}$due to the mixing between the symmetric and asymmetric stretching modes. The $\mathrm{OH}$ stretching mode in free $\mathrm{HIO}_{3}$ and $\mathrm{HIO}_{2}$ were predicted to be 3780 and $3827 \mathrm{~cm}^{-1}$, respectively. Upon complexation, these are redshifted by 72 and 52 $\mathrm{cm}^{-1}$ (Figure 7), indicating a noticeable elongation of the $\mathrm{HO}$ bond length. The Mo6-2X calculated $\mathrm{OH}$ bond length in free $\mathrm{HIO}_{3}$ and $\mathrm{HIO}_{2}$ were predicted to be 0.9720 and $0.9677 \AA$, respectively. Upon complexation, these distances are increased by 0.0045 and $0.0042 \AA$, respectively. Similar conclusions were drawn from the MP2 results (Figure S9 and Table $\mathbf{S}_{4}$ ).

Atmospheric implications. The role of halogen bonding in drug design, material discovery and catalysis is well appreciated. ${ }^{32-36}$ Some studies have explored the role of halogen bonding in gas phase atmospheric chemistry, e.g. in the formation of hydrated HOX clusters $(\mathrm{X}=\mathrm{Cl}, \mathrm{Br})^{37}$, iodine oxide clusters and hydrated iodine oxide clusters ${ }^{4}$, and others ${ }^{38}$. It has been recently proposed that halogen bonding may play a role in chemical transformations in particles ${ }^{38}$. Our work is the first inspecting in detail these unusual interactions in the context of atmospheric aerosol surface chemistry.

Our dynamic simulations indicate that the iodine atom of $\mathrm{IONO}_{2}$ interacts with interfacial water oxygen through halogen bonding, supporting the high accommodation coefficient assumed in atmospheric models ${ }^{12}$. In addition, $\mathrm{IONO}_{2}$ can act as a halogen bond donor and interact with oxygen-rich iodine acids or oxides or other species in the air-water interface. We have shown that $\mathrm{IONO}_{2}$ can interact with gas phase $\mathrm{HIO}_{2}$ or $\mathrm{HIO}_{3}$, or with $\mathrm{IO}_{3}{ }^{-}$present at the aerosol surface. Similarly, it could also interact with iodine oxides such as $\mathrm{I}_{2} \mathrm{O}_{\mathrm{y}}(\mathrm{y}=2-4)$, resulting in new complexes. The calculated electrostatic potential maps for $\mathrm{I}_{2} \mathrm{O}_{2}$ and $\mathrm{I}_{2} \mathrm{O}_{3}$ suggest that these interactions are viable and are expected to be relatively stronger in $\mathrm{I}_{2} \mathrm{O}_{3}$ (Figure 8). This also indicates a high $\mathrm{IONO}_{2}$ reactive uptake coefficient. The ability of $\mathrm{IONO}_{2}$ to stick to aqueous aerosol surface may also modify substantially its photochemistry.

Previous atmospheric modelling studies have assumed that $\mathrm{IONO}_{2}$ would hydrolyze on aqueous

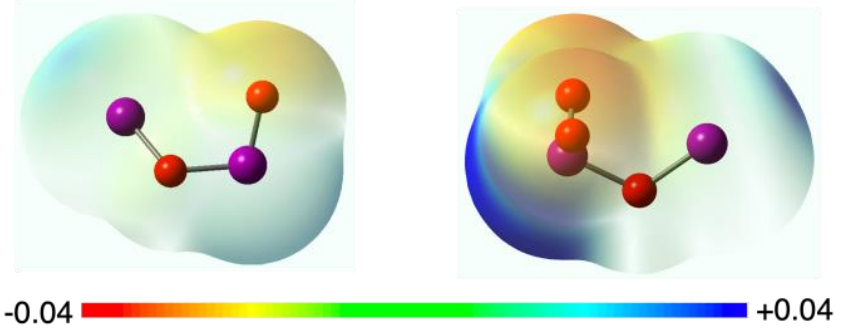

Figure 8. The calculated molecular electrostatic potential maps of $\mathrm{I}_{2} \mathrm{O}_{2}$ and $\mathrm{I}_{2} \mathrm{O}_{3}$. Red indicates negative electrostatic potential; blue refers to positive electrostatic potential. The electrostatic potential surfaces were calculated at an isovalue of 0.004 .

aerosol, resulting in iodide ions ${ }^{12}$. These react in the aqueous phase with available halide anions in the presence of sufficient acidity, forming di-halogens, and thus resulting in halogen activation. Future studies should investigate the fate of halogen-bound complexes at the air-water interface. After uptake, they may result in the formation of iodate rather than iodide. For example, $\mathrm{IO}_{3}-\mathrm{IONO}_{2}$ may decompose into $\mathrm{I}_{2} \mathrm{O}_{3}$, which could subsequently hydrolyze, forming $\mathrm{HIO}_{3}$ and eventually $\mathrm{IO}_{3}{ }^{-}$. Currently the factors controlling the iodate to iodide ratio in aerosol and rain water are not understood ${ }^{1}$, although recent particulate iodine observations in the upper troposphere and lower stratosphere show this fraction to be dominated by iodate ${ }^{39}$. Furthermore, as gas phase molecules, $\mathrm{HIO}_{x}-\mathrm{IONO}_{2}$ may photolyze or, in coastal environments, participate in new particle formation. Our work should open up new research avenues in further exploring the role of these unusual non-covalent interactions in atmospheric chemistries.

A related aspect is the role of halogen bonding in the formation of cluster anions in ambient chemical ionization mass spectrometry (CIMS). A popular CIMS ionization scheme employs iodine for the detection of di-halogens (excluding $\mathrm{I}_{2}$ ), nitric acid $\left(\mathrm{HNO}_{3}\right)$, and organic acids. This is achieved by the formation of complexes that can be easily identified in the mass spectra, provided that a primary standard is available. Some of these complexes show halogen-bonding ${ }^{38}$. Other ionization schemes employing bromide, acetate or nitrate ions are more suitable for the detection of ambient iodine species, e.g. of gas phase $\mathrm{HIO}_{3}$ by nitrate CIMS as $\mathrm{IO}_{3}^{-}$has been reported ${ }^{8}$. The halogen-bonded $\mathrm{IO}_{3}^{-}-$ $\mathrm{IONO}_{2}$ adduct studied in the present work may be as well reached from $\mathrm{I}_{2} \mathrm{O}_{3}+\mathrm{NO}_{3}{ }^{-}$, in such a way that these reagents connect without barriers with the products $\mathrm{IO}_{3}{ }^{-}+\mathrm{IONO}_{2}$ (a bimolecular nucleophilic substitution). Thus, a major iodine oxide such as $\mathrm{I}_{2} \mathrm{O}_{3}{ }^{5}$ is also likely to produce $\mathrm{IO}_{3}^{-}$, potentially confounding the interpretation of nitrate CIMS mass spectra. Considering that the existing field measurement techniques are very sensitive, but not entirely selective to establish the chemical composition of molecular clusters, computational chemistry could play a crucial role in illuminating the interpretation of observations. 


\section{CONCLUSIONS}

The $\mathrm{HIO}_{3}-\mathrm{IONO}_{2}$ and $\mathrm{HIO}_{2}-\mathrm{IONO}_{2}$ interactions as well as the dynamics behavior of $\mathrm{IONO}_{2}$ at the air-water interface were explored using molecular simulations. Interestingly, the iodine atom of $\mathrm{IONO}_{2}$ interacts with $\mathrm{HIO}_{2}$ or $\mathrm{IO}_{3}{ }^{-}$present at the aerosol surface or interfacial water molecules through halogen bonding. The gas-phase analysis of $\mathrm{IONO}_{2}$ complexes suggest that the iodine atom of $\mathrm{IONO}_{2}$ in these complexes behave like a proton, which contributes towards its halogen bonding behavior. This halogen bonding may result in a high $\mathrm{IONO}_{2}$ reactive uptake coefficient at the aqueous aerosol surface, which may also modify substantially its photochemistry. The $\mathrm{IONO}_{2}-$ induced halogen bonding with potential iodine species could also result in new particle formation in coastal environments. In short, our work should open up new research avenues in further exploring the role of these unusual non-covalent interactions in atmospheric chemistries.

\section{ASSOCIATED CONTENT}

Supporting Information. Movies showing the trajectories of the aqueous phase dynamics of the $\mathrm{HIO}_{3}$, $\mathrm{IONO}_{2}, \mathrm{HIO}_{3}-\mathrm{IONO}_{2}$, and $\mathrm{HIO}_{2}-\mathrm{IONO}_{2}$ at the air-water interface, time evolution profiles of key distances involved in the interfacial $\mathrm{HIO}_{3}-\mathrm{IONO}_{2}$ and $\mathrm{HIO}_{2}-\mathrm{IONO}_{2}$ complexes, Mo6-2X calculated NBO charges, rotational constants, zero-point correction, thermal correction to Gibbs free energy, $\operatorname{CCSD}(\mathrm{T})$ calculated electronic energies, MP2 calculated IR spectra of key iodine species, tables containing Mo6-2X and MP2 calculated harmonic vibrational frequencies, and optimized geometries of various species examined in the present work. The Supporting Information is available free of charge on the ACS Publications website.

\section{AUTHOR INFORMATION}

\section{Corresponding Author}

frjoseph@sas.upenn.edu

\section{Funding Sources}

\section{Notes}

Authors declare no competing financial interest.

\section{ACKNOWLEDGMENT}

This work was supported by the University of Nebraska Holland Computing Center.

\section{REFERENCES}

1. Saiz-Lopez, A.; Plane, J. M. C.; Baker, A.; Carpenter, L.; von Glasow, R.; Gómez Martín, J. C.; McFiggans, G.; Saunders, R. Atmospheric chemistry of iodine. Chem. Rev. 2012, 112, 1773-1804.

2. Seto, F. Y. B.; Duce, R. A. A laboratory study of iodine enrichment on atmospheric sea-salt particles produced by bubbles. J. Geophys. Res. 1972, 77, 5339.

3. Jimenez, J. L.; Bahreini, R.; Cocker, D. R., III; Zhuang, H.; Varutbangkul, V.; Flagan, R. C.; Seinfeld, J. H.; O'Dowd, C. D.; Hoffmann, T. New particle formation from photooxidation of diiodomethane $\left(\mathrm{CH}_{2} \mathrm{I}_{2}\right)$ J. Geophys. Res. 2003, 108, 4318.

4. Galvez, O.; Gómez Martín, J. C.; Gomez, P. C.; Saiz-Lopez, A.; Pacios, L. F. A theoretical study on the formation of iodine oxide aggregates and monohydrates. Phys. Chem. Chem. Phys. 2013, 15, 15572-15583.

5. Gómez Martín, J. C.; Galvez, O.; Baeza-Romero, M. T.; Ingham, T.; Plane, J. M. C.; Blitz, M. A. On the mechanism of iodine oxide particle formation. Phys. Chem. Chem. Phys. 2013, 15, 1561215622.

6. Kumar, R.; Saunders, R. W.; Mahajan, A. S.; Plane, J. M. C.; Murray, $B$. Physical properties of iodate solutions and the deliquescence of crystalline $\mathrm{I}_{2} \mathrm{O}_{5}$ and $\mathrm{HIO}_{3}$. J. Atmos. Chem. Phys. 2010, 10, 12251.

7. Saunders, R. W.; Mahajan, A. S.; Gómez Martín, J. C.; Kumar, R.; Plane, J. M. C. Z. Studies of the formation and growth of aerosol from molecular iodine precursor. Phys. Chem. 2010, 224, 1095.

8. Sipilä, M.; Sarnela, N.; Jokinen, T.; Henschel, H.; Junninen, H.; Kontkanen, J.; Richters, S.; Kangasluoma, J.; Franchin, A.; Peräkylä, O.; Rissanen, M. P.; Ehn, M.; Vehkamäki, H.; Kurten, T.; Berndt, T.; Petäjä, T.; Worsnop, D.; Ceburnis, D.; Kerminen, V.-M.; Kulmala, M.; O'Dowd, C. Molecular-scale evidence of aerosol particle formation via sequential addition of $\mathrm{HIO}_{3}$. Nature 2016, 537, 532-534.

9. Kumar, M.; Saiz-Lopez, A.; Francisco, J. S. Single-molecule catalysis revealed: Elucidating the mechanistic framework for the formation and growth of atmospheric iodine oxide aerosols in gasphase and aqueous surface environments. J. Am. Chem. Soc. 2018, 140, 14704-14716.

10. Mahajan, A. S.; Sorribas, M.; Gómez Martín, J. C.; MacDonald, S. M.; Gil, M.; Plane, J. M. C.; Saiz-Lopez, A. Concurrent observations of atomic iodine, molecular iodine and ultrafine particles in a coastal environment. Atmos. Chem. Phys. 2010, 10, 27227.

11. McFiggans, G.; Bale, C. S. E.; Ball, S. M.; Beames, J. M.; Bloss, W. J.; Carpenter, L. J.; Dorsey, J.; Dunk, R.; Flynn, M. J.; Furneaux, K. L.; Gallagher, M. W.; Heard, D. E.; Hollingsworth, A. M.; Hornsby, K.; Ingham, T.; Jones, C. E.; Jones, R. L.; Kramer, L. J.; Langridge, J. M.; Leblanc, C.; LeCrane, J. P.; Lee, J. D.; Leigh, R. J.; Longley, I.; Mahajan, A. S.; Monks, P. S.; Oetjen, H.; Orr-Ewing, A. J.; Plane, J. M. C.; Potin, P.; Shillings, A. J. L.; Thomas, F.; von Glasow, R.; Wada, R.; Whalley, L. K.; Whitehead, J. D. lodine-mediated coastal particle formation: an overview of the reactive halogens in the marine boundary layer (RHaMBLe) Roscoff coastal study. Atmos. Chem. Phys. 2010, 10, 2975.

12. Vogt, R.; Sander, R.; von Glasow, R.; Crutzen, P. J. lodine chemistry and its role in halogen activation and ozone loss in the marine boundary layer: A model study. J. Atmos. Chem. 1999, 32, 375395.

13. Donaldson, D. J.; Vaida, V. The influence of organic films at the air-aqueous boundary on atmospheric processes. Chem. Rev. 2006, 106, 1445-1461.

14. Ravishankara, A. R. Heterogeneous and multiphase chemistry in the troposphere. Science 1997, 276, 1058-1065.

15. Zhong, J.; Kumar, M.; Zeng, X. C.; Francisco, J. S. Insight into chemistry on cloud/aerosol water surfaces. Acc. Chem. Res. 2018, 51, 1229-1237.

16. Zhong J.; Kumar, M.; Anglada, J. M.; Martins-Costa, M. T. C.; RuizLòpez, M. F.; Zeng, X. C.; Francisco, J. S. Atmospheric spectroscopy and photochemistry at environmental water interfaces. Ann Rev. Phys. Chem. 2019, 70, 45-69.

17. VandeVondele, J.; Krack, M.; Mohamed, F.; Parrinello, M.; Chassaing, T.; Hutter, J. Quickstep: fast and accurate density functional calculations using a mixed Gaussian and plane waves approach. Comput. Phys. Commun. 2005, 167, 103.

18. Perdew, J. P.; Wang, Y. Pair-distribution function and its couplingconstant average for the spin-polarized electron gas. Phys. Rev. $B$ 1992, 45, 13244.

19. Perdew, J. P.; Burke, K.; Ernzerhof, M., Generalized gradient approximation made simple. Phys. Rev. Lett. 1996, 77, 3865. 
20. Grimme, S. Accurate description of van der Waals complexes by density functional theory including empirical corrections. J. Com put. Chem. 2004, 25, 1463.

21. Grimme, S. Semiempirical GGA-type density functional constructed with a long-range dispersion correction. J. Comput. Chem. 2006, 27, 1787.

22. Goedecker, S.; Teter, M.; Hutter, J. Separable dual-space Gaussian pseudopotentials. Phys. Rev. B 1996, 54, 1703.

23. Hartwigsen, C.; Goedecker, S.; Hutter, J. Relativistic separable dual-space Gaussian pseudopotentials from H to Rn. Phys. Rev. B 1998, 58, 3641 .

24. Frisch, M. J.; Trucks, G. W.; Schlegel, H. B.; Scuseria, G. E.; Robb M. A.; Cheeseman, J. R.; Scalmani, G.; Barone, V.; Mennucci, B. Petersson, G. A.; Nakatsuji, H.; Caricato, M.; Li, X.; Hratchian, H. P.; Izmaylov, A. F.; Bloino, J.; Zheng, G.; Sonnenberg, J. L.; Hada, M.; Ehara, M.; Toyota, K.; Fukuda, R.; Hasegawa, J.; Ishida, M.; Nakajima, T.; Honda, Y.; Kitao, O.; Nakai, H.; Vreven, T.; Montgomery, J. A., Jr.; Peralta, J. E.; Ogliaro, F.; Bearpark, M.; Heyd J. J.; Brothers, E.; Kudin, K. N.; Staroverov, V. N.; Kobayashi, R Normand, J.; Raghavachari, K.; Rendell, A.; Burant, J. C.; lyengar S. S.; Tomasi, J.; Cossi, M.; Rega, N.; Millam, J. M.; Klene, M.; Knox, J. E.; Cross, J. B.; Bakken, V.; Adamo, C.; Jaramillo, J.; Gomperts, R.; Stratmann, R. E.; Yazyev, O.; Austin, A. J.; Cammi, R.; Pomelli, C.; Ochterski, J. W.; Martin, R. L.; Morokuma, K.; Zakrzewski, V. G.; Voth, G. A.; Salvador, P.; Dannenberg, J. J.; Dapprich, S.; Daniels, A. D.; Farkas, O.; Foresman, J. B.; Ortiz, J. V.; Cioslowski, J.; Fox, D. J. Gaussian 09, Revision D.01; Gaussian Inc.: Wallingford, CT, 2009.

25. Zhao, Y.; Truhlar, D. G., The M06 suite of density functionals for main group thermochemistry, thermochemical kinetics, noncovalent interactions, excited states, and transition elements: two new functionals and systematic testing of four M06-class functionals and 12 other functionals. Theor. Chem. Acc. 2008, 120, 215-241.

26. Dunning Jr., T. H. Gaussian basis sets for use in correlated molecular calculations. I. the atoms boron through neon and hydrogen. J. Chem. Phys. 1989, 90, 1007

27. Kendall, R. A.; Dunning Jr., T. H.; Harrison, R. J. Electron affinities of the first-row atoms revisited. systematic basis sets and wave functions. J. Chem. Phys. 1992, 96, 6796.

28. Noga, J.; Bartlett, R. J. The full CCSDT model for molecular electronic structure. J. Chem. Phys. 1987, 86, 7041
29. Rong, H.; Liu, J.; Zhang, Y.; Du, L.; Zhang, X; Li, Z. Nucleation mechanisms of iodic acid in clean and polluted coastal regions. Chemosphere 2020, 253, 126743.

30. Perrin, D. D. Ionization constants of inorganic acids and bases in aqueous solution, second edition, Pergamon, Oxford, 1982.

31. Villard, A.; Khanniche, S.; Fortin, C.; Cantrel, L.; Cernusák, I. Louis, F. A theoretical study of the microhydration processes of iodine nitrogen oxides. Int. J. Quantum Chem. 2019, 119, 25792.

32. Kolár, M. H.; Hobza, P. Computer modeling of halogen bonds and other $\sigma$-hole interactions. Chem. Rev. 2016, 116, 5155-5187.

33. Cavallo, G.; Metrangolo, P.; Milani, R.; Pilati, T.; Priimagi, A.; Resnati, G.; Terraneo, G. The halogen bond. Chem. Rev. 2016, 116, 2478-2601.

34. Wang, H.; Wang, W.; Jin, W. J. $\sigma$-Hole Bbnd vs m-hole bond: A comparison based on halogen bond. Chem. Rev. 2016, 116, 5072-5104.

35. Gilday, L. C.; Robinson, S. W.; Barendt, T. A.; Langton, M. J.; Mullaney, B. R.; Beer, P. D. Halogen bonding in supramolecular chemistry. Chem. Rev. 2015, 115, 7118-7195.

36. Metrangolo, P.; Neukirch, H.; Pilati, T.; Resnati, G. Halogen bonding based recognition processes: A world parallel to hydrogen bonding. Acc. Chem. Res. 2005, 38, 386-395.

37. Wolf, M. E.; Zhang, B.; Turney, J. M.; Schaefer, H. F. A comparison between hydrogen and halogen bonding: the hypohalous acid-water dimers, $\mathrm{HOX}-\mathrm{H}_{2} \mathrm{O}(\mathrm{X}=\mathrm{F}, \mathrm{Cl}, \mathrm{Br})$. Phys. Chem. Chem. Phys. 2019, 21, 6160-6170.

38. Ganske, J. A.; Wingen, L. M.; Perraud, V.; Finlayson-Pitts, B. J. Role of gas-phase halogen bonding in ambient chemical ionization mass spectrometry utilizing iodine. ACS Earth Space Chem. 2019 3, 1315-1328

39. Koenig, T. K.; Baidar, S.; Campuzano-Jost, P.; Cuevas, C. A.; Dix B.; Fernandez, R. P.; Guo, H.; Hall, S. R.; Kinnison, D.; Nault, B. A.; Ullmann, K.; Jimenez, J. L.; Saiz-Lopez, A.; Volkamer, R. Quantitative detection of iodine in the stratosphere. Proc. Natl. Acad. Sci. U. S. A. 2020, 117, 1860-1866. 


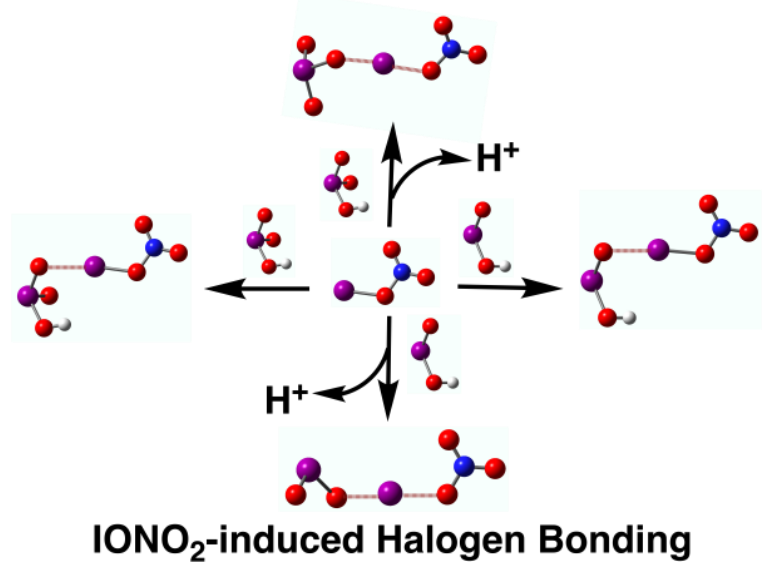

